\title{
Advances in quantitative magnetic resonance imaging-based biomarkers for Alzheimer disease
}

\author{
Bradford C Dickerson*
}

\begin{abstract}
A critical goal of Alzheimer disease research is to identify disease biomarkers that can be used in clinical trials to assist in the adjudication of treatment effects. While clinical validation remains a goal for many potential Alzheimer disease biomarkers, the rapid proliferation of markers has sparked comparative efforts as well. New data acquisition methods and sophisticated image-processing algorithms are poised to make a substantial impact on our ability to make precise measurements of the structure and function of regions within the living human brain and their connections and chemical composition. This commentary provides a perspective on a recently published paper and how it illustrates progress and challenges in the field.
\end{abstract}

A decade ago, Nick Fox and colleagues [1] used sample size estimates for hypothetical disease-modifying clinical trials to call attention to the important value of magnetic resonance imaging (MRI)-based imaging biomarkers for Alzheimer disease (AD). Since then, this approach has been employed to demonstrate the potential value of new methods for measuring anatomic, metabolic, and other putative $\mathrm{AD}$ biomarkers [2]. A new paper illustrates progress and challenges in this area [3].

The authors measured longitudinal change in cortical and subcortical volume with an interesting new method that takes advantage of a precise image registration algorithm (comparable to tensor-based morphometry, or TBM). A so-called volume-change field is produced at each voxel and then is averaged over a set of-in some cases large-a priori-defined anatomic regions of interest

*Correspondence: bradd@nmr.mgh.harvard.edu

Frontotemporal Dementia Unit, Departments of Neurology and Psychiatry, Massachusetts Alzheimer's Disease Research Center, Athinoula A. Martinos Center for Biomedical Imaging, Massachusetts General Hospital and Harvard Medical School, 149 13th Street, Charlestown, MA 02129, USA
(ROIs) to obtain the percentage change from baseline. This averaging step is somewhat puzzling, however, particularly given the stated precision of registration and concept of this method as providing 'subregion' measures. The $a$ priori atlas [4] provides a valuable service in that it does an excellent job of automating a cumbersome process of identifying neuroanatomic ROIs in individual scans. However, many of the cortical ROIs are quite large and most neurodegenerative diseases do not respect the anatomic boundaries of these ROIs-only subregions tend to be affected, and some effects span multiple ROIs. Thus, the power of this precise registration method may be reduced by constraining it to anatomic ROIs, rather than to ROIs generated from the known effects of $A D$ itself ('disease signature' effects), such as have been described for both MRI $[5,6]$ and fluorodeoxyglucosepositron emission tomography (FDG-PET) data [7]. This point is illustrated in a recent TBM study [8] showing that an anatomically defined ROI in the temporal lobe required consistently higher samples than a disease signature' ROI defined from an independent longitudinal AD patient sample (Table 1 of [8]).

Although differences in sample size estimation methods make it difficult to directly compare the present study [3] to that of Fox and colleagues (2000) [1], a cursory examination of the whole-brain measure in $\mathrm{AD}$ patients from Table 1 of the present study $(\mathrm{n}=189)$ with Table 1 of Fox and colleagues $(n=168)$ does not suggest an obvious advantage. With more closely matched sample size estimation calculations, comparison with the recent TBM study [8] demonstrates that the present method requires consistently larger sample sizes for both $\mathrm{AD}$ and mild cognitive impairment. (Compare Tables 1 and 2 of the present study [3] with Table 1 of the TBM study [8].) Nevertheless, the new method ultimately may make important contributions with further development.

How can we decide whether a new marker adds value? Sample size estimation is one approach since it reflects the size of the biologic or clinical effect of interest and its variability (subsuming both biologic and measurement variability).

One important challenge in comparing papers using such analyses is that many of the investigator-specified 
variables differ in addition to the parameters of relevance. Larger or smaller sample size estimates can be derived from the same measures simply by choosing different hypothetical drug effects. If sample size estimates are not recalculated using original data, it can be difficult to directly compare such measures, requiring readers to resort to comparing the atrophy rates and standard deviations, which also may be variably reported.

In large part because of the profound advances in infrastructure and standards being developed by the Alzheimer's Disease Neuroimaging Initiative (ADNI), it is now possible to efficiently perform comparisons of increasingly sophisticated measures derived from computational processing of MRI and PET data. Yet it can still be difficult to compare measures because different subsets of subjects may be included in any analysis. Laurel Beckett, Danielle Harvey, and colleagues affiliated with the ADNI biostatistics core are finishing an analysis that emphasizes the need to compare markers on a common set of subjects and demonstrates a method not only for characterizing biomarkers but also for statistically testing for differences between measures. These important advances should provide a framework that makes it easier to determine the pros and cons of new imaging analytic methods, which are advancing in at least two domains.

First, they are becoming more refined with respect to anatomy. Since the pioneering efforts of the neuroanatomist Constantin von Economo, who not only exhaustively mapped cortical cytoarchitecture but also painstakingly measured the thickness of cortical regions and laminae [9], anatomists have been interested in measures of the size of different brain regions. Although anatomists and pathologists over the years have observed cortical thinning in $\mathrm{AD}[10,11]$, it has proven very challenging to measure in vivo. These issues have been largely solved in recent years through advanced computational procedures [12-14]. Since the volume of a gyral cortical region reflects both its thickness and surface area and since AD appears to affect thickness more prominently than surface area [15] (although this issue deserves further study), it also stands to reason that measures of thickness may be particularly sensitive to neurodegenerative disease effects. It is somewhat surprising that computational methods perform as well as they do in detecting submillimeter disease effects with raw voxel sizes of at least $1 \mathrm{~mm}$; the precision of these measures will undoubtedly improve as the resolution of MRI data acquisition improves.

Second, advanced methods for mapping the spatial patterns of disease will likely enhance our ability to differentiate the effects of one disease from those of another or from normal aging. A number of these methods are being developed and they are derived mostly from machine learning and pattern recognition algorithms and increasingly are being used in applications such as face or voice recognition. Initial applications of these methods to $\mathrm{AD}$ and related disorders have been very promising [1618], and these types of procedures will likely have an important impact on improving the specificity of imaging biomarkers in AD.

Ultimately, the goal of this research is to enable diseasemodifying treatments to be identified more efficiently. A large and growing community of investigators in the field believes that we not only need to measure brain changes that can provide a glimpse of any such benefits of a given intervention but also need to realize the complexities of linking these changes to clinical benefit [19].

\section{Abbreviations}

AD, Alzheimer disease; ADNI, Alzheimer's Disease Neuroimaging Initiative; MRI, magnetic resonance imaging; PET, positron emission tomography; $\mathrm{ROI}$, region of interest; TBM, tensor-based morphometry.

\section{Competing interests}

The author declares that he has no competing interests.

\section{Acknowledgments}

This work was supported by grants from the National Institute on Aging (R01AG29411 and R21-AG29840) and the Alzheimer's Association.

Published: 6 July 2010

\section{References}

1. Fox NC, Cousens S, Scahill R, Harvey RJ, Rossor MN: Using serial registered brain magnetic resonance imaging to measure disease progression in Alzheimer disease: power calculations and estimates of sample size to detect treatment effects. Arch Neurol 2000, 57:339-344.

2. Jack CR Jr., Slomkowski M, Gracon S, Hoover TM, Felmlee JP, Stewart K, Xu Y, Shiung M, O'Brien PC, Cha R, Knopman D, Petersen RC: MRI as a biomarker of disease progression in a therapeutic trial of milameline for AD. Neurology 2003, 60:253-260.

3. Holland D, Brewer JB, Hagler DJ, Fenema-Notestine C, Dale AM; the Alzheimer's Disease Neuroimaging Initiative, Weiner M, Thal L, Petersen R, Jack CR Jr., Jagust W, Trojanowki J, Toga AW, Beckett L, Green RC, Gamst A, Potter WZ, Montine T, Anders D, Bernstein M, Felmlee J, Fox N, Thompson P, Schuff N, Alexander G, Bandy D, Koeppe RA, Foster N, Reiman EM, Chen K, et al:: Subregional neuroanatomical change as a biomarker for Alzheimer's disease. Proc Natl Acad Sci U S A 2009, 106:20954-20959.

4. Desikan RS, Ségonne F, Fischl B, Quinn BT, Dickerson BC, Blacker D, Buckner RL, Dale AM, Maguire RP, Hyman BT, Albert MS, Killiany RJ: An automated labeling system for subdividing the human cerebral cortex on MRI scans into gyral based regions of interest. Neuroimage 2006, 31:968-980.

5. Bakkour A, Morris JC, Dickerson BC: The cortical signature of prodromal AD: regional thinning predicts mild AD dementia. Neurology 2009, 72:1048-1055.

6. Dickerson BC, Bakkour A, Salat DH, Feczko E, Pacheco J, Greve DN, Grodstein F, Wright Cl, Blacker D, Rosas HD, Sperling RA, Atri A, Growdon JH, Hyman BT, Morris JC, Fischl B, Buckner RL: The cortical signature of Alzheimer's disease: regionally specific cortical thinning relates to symptom severity in very mild to mild AD dementia and is detectable in asymptomatic amyloidpositive individuals. Cereb Cortex 2009, 19:497-510.

7. Chen K, Langbaum JB, Fleisher AS, Ayutyanont N, Reschke C, Lee W, Liu X, Bandy D, Alexander GE, Thompson PM, Foster NL, Harvey DJ, de Leon MJ, Koeppe RA, Jagust WJ, Weiner MW, Reiman EM; Alzheimer's Disease Neuroimaging Initiative: Twelve-month metabolic declines in probable Alzheimer's disease and amnestic mild cognitive impairment assessed using an empirically pre-defined statistical region-of-interest: findings from the Alzheimer's Disease Neuroimaging Initiative. Neuroimage 2010, 51:654-64.

8. Hua X, Lee S, Hibar DP, Yanovsky I, Leow AD, Toga AW, Jack CR Jr, Bernstein MA, Reiman EM, Harvey DJ, Kornak J, Schuff N, Alexander GE, Weiner MW, 
Thompson PM; Alzheimer's Disease Neuroimaging Initiative: Mapping Alzheimer's disease progression in $1309 \mathrm{MRI}$ scans: power estimates for different inter-scan intervals. Neuroimage 2010, 51:63-75.

9. von Economo C: Cellular Structure of the Human Cerebral Cortex. Basel: S. Karger AG; 2009

10. Regeur L: Increasing loss of brain tissue with increasing dementia: a stereological study of post-mortem brains from elderly females. Eur Neurol 2000, 7:47-54.

11. Brun A, Gustafson L: Distribution of cerebral degeneration in Alzheimer's disease. A clinico-pathological study. Arch Psychiatr Nervenkr 1976, 223:15-33.

12. Fischl B, Dale AM: Measuring the thickness of the human cerebral cortex from magnetic resonance images. Proc Natl Acad Sci U S A 2000, 97:11050-11055.

13. Kabani N, Le Goualher G, MacDonald D, Evans AC: Measurement of cortical thickness using an automated 3-D algorithm: a validation study. Neuroimage 2001, 13:375-380.

14. Thompson PM, Mega MS, Woods RP, Zoumalan Cl, Lindshield CJ, Blanton RE, Moussai J, Holmes CJ, Cummings JL, Toga AW: Cortical change in Alzheimer's disease detected with a disease-specific population-based brain atlas. Cereb Cortex 2001, 11:1-16.

15. Dickerson BC, Feczko E, Augustinack JC, Pacheco J, Morris JC, Fischl B,
Buckner RL: Differential effects of aging and Alzheimer's disease on medial temporal lobe cortical thickness and surface area. Neurobiol Aging 2009, 30:432-440.

16. Vemuri P, Gunter JL, Senjem ML, Whitwell JL, Kantarci K, Knopman DS, Boeve $B F$, Petersen RC, Jack CR Jr.: Alzheimer's disease diagnosis in individual subjects using structural MR images: validation studies. Neuroimage 2008, 39:1186-1197.

17. Wilson SM, Ogar JM, Laluz V, Growdon M, Jang J, Glenn S, Miller BL, Weiner MW, Gorno-Tempini ML: Automated MRI-based classification of primary progressive aphasia variants. Neuroimage 2009, 47:1558-1567.

18. Davatzikos C, Resnick SM, Wu X, Parmpi P, Clark CM: Individual patient diagnosis of $A D$ and FTD via high-dimensional pattern classification of MRI. Neuroimage 2008, 41:1220-1227.

19. Aisen PS: Alzheimer's disease therapeutic research: the path forward. Alzheimers Res Ther 2009, 1:2.

doi:10.1186/alzrt45

Cite this article as: Dickerson BC: Advances in quantitative magnetic resonance imaging-based biomarkers for Alzheimer disease. Alzheimer's Research \& Therapy 2010, 2:21. 